\title{
Duelo de Cortes: El caso "Fontevecchia" y el valor de las sentencias de la Corte Interamericana
}

Román De Antoni

El pasado 14 de febrero de 2017, la nueva composición de la Corte Suprema de Justicia de la Nación ${ }^{1}$ dictó el fallo "Ministerio de Relaciones Exteriores y Culto s/informe sentencia dictada en el caso 'Fontevecchia y D'Amico vs. Argentina' por la Corte Interamericana de Derechos Humanos", en donde ha adoptado una novedosa postura respecto al valor de los pronunciamientos de organismos jurisdiccionales internacionales cuando ordenan "dejar sin efecto" decisiones adoptadas en la justicia nacional. Nueve meses después, la Corte Interamericana ${ }^{2}$ consideró que el Estado argentino incumplió la medida. Ambos pronunciamientos han reavivado la discusión en la doctrina constitucionalista respecto al alcance de la soberanía jurídica de los estados y su relación con el derecho internacional. ¿Cuál es el "nuevo valor" de las sentencias de la Corte Interamericana para la CSJN? ¿Hay un cambio de postura en la decisión del tribunal?

\section{Antecedentes del fallo de la CSJN}

La Dirección de Derechos Humanos del Ministerio de Relaciones Exteriores y Culto solicitó a la Corte Suprema de Justicia de la Nación que, como consecuencia del fallo de la Corte Interamericana dictado en el año 2011 en la causa "Fontevecchia y otros c/República Argentina" ${ }^{3}$, se dejara sin efecto una sentencia firme del año 2001 en la que CSJN confirmó una condena civil

\footnotetext{
En adelante "CSJN".

2 En adelante "Corte IDH".

3 Corte IDH. Caso Fontevecchia y D’Amico Vs. Argentina. Sentencia del 29/11/11.
} 
de indemnización por daños y perjuicios contra los periodistas Jorge Fontevecchia y Carlos D'Amico por violación a la vida privada del ex presidente Carlos Menem, a raíz de una publicación periodística en la revista "Noticias" en la que se contaba acerca de un hijo no reconocido del ex presidente -Carlos Menen Jr.-.

En esa decisión, la Corte Interamericana -luego que el proceso transite durante más de 10 años por las instancias ordinarias del sistema interamericano (SIDH)- declaró que el Estado argentino violó el derecho a la libertad de expresión de los peticionantes (art. 13, CADH), ordenando, cómo uno de los modos de reparación a la víctimas, dejar sin efecto la condena civil impuesta a Fontevecchia y D’Amico y todas sus consecuencias.

La CSJN, a través del voto conjunto de los jueces Ricardo Lorenzetti, Elena Highton de Nolasco y Carlos Rosenkrantz, y el voto propio del juez Horacio Rosattti, ${ }^{4}$ resolvió desestimar el pedido de revocación de la Secretaría de Derechos Humanos, bajo las siguientes afirmaciones, las cuales a continuación pasaré a resumir:

\section{a) Valor de las sentencias de la Corte Interamericana de Derechos Humanos (Corte IDH):}

Las sentencias dictadas en procesos contradictorios contra el Estado Argentino son "obligatorias" y "vinculantes", siempre y cuando: (i) Sean dictadas "dentro del marco de sus potestades remediables" (Considerando $\mathrm{N}^{\circ}$ 6); (ii) Sean sancionadas dentro de las funciones materiales que el art. 63 de la $\mathrm{CADH}$ le concede a dicho órgano internacional (considerando $\mathrm{N}^{\circ} 20$ );

Dicho de otro modo, la Corte Nacional reconoce el valor jurídico que poseen las sentencias de la Corte IDH, pero ella misma se arroga una nueva competencia: determinar cuándo ese tribunal actúa dentro de las competencias del art. 63 de la Convención Americana.

\footnotetext{
4 Únicamente Maqueda voto en disidencia.
} 
b) Alcance de doctrina de la "Cuarta Instancia":

Para la CSJN, la Corte IDH no constituye una "cuarta instancia" que revisa o anula decisiones jurisdiccionales estatales sino que resulta "subsidiaria, coadyuvante y complementaria" (Considerando $\mathrm{N}^{\circ}$ 8); En ese sentido, la CSJN entiende que dejar sin efecto -o en sus propias palabras "revocar"- una decisión propia, implica "transformar a la Corte IDH en una cuarta instancia, en clara violación a los principios estructurales del Sistema Interamericano" (Considerando No 11); "La idea de revocación se encuentra en el centro mismo del concepto de "cuarta instancia", en tanto una instancia judicial superior supone la capacidad de revisar las decisiones del inferior" (considerando $\mathrm{N}^{\mathrm{o}} 11$ );

Con respecto a la doctrina de la llamada "cuarta instancia", vale decir que la misma no ha tenido desarrollo profundo en la jurisprudencia de la Corte IDH, pero "sí" en la de la Comisión Interamericana de Derechos Humanos (CIDH), organismo que ha afirmado que su función no es ser -en principio- "una cuarta instancia para resolver errores de becho o de derecho cometidos por los tribunales locales dentro de la esfera de su competencia a menos que ellos constituyan violaciones a la Convención" como puede ser afectaciones al debido proceso o a la protección judicial. En otros términos, siempre que se aleguen violaciones a derechos contemplados en ese instrumento internacional los organismos del sistema interamericano pueden revisar las decisiones de los tribunales nacionales.

\section{c) Limite material a la competencia de la Corte} Interamericana:

La CSJN sostiene que el tribunal interamericano se extralimitó en su función, en tanto al "revocar" una sentencia local incurrió en un "mecanismo que no se encuentra previsto por el texto convencional" (Considerando $\mathrm{N}^{\mathrm{o}} 12$ ); Así, sostuvo -luego

\footnotetext{
5 CIDH, Informe № 39/96, Caso № 11.673, Marzioni, Argentina, 15 de octubre de 1996, párrafos 50-51
} 
de citar el art. 63.1 de la CADH- que la Convención Americana "no contempla la posibilidad que la Corte Interamericana deje sin efecto una sentencia dictada en sede nacional" (considerando $\mathrm{N}^{\circ}$ 13) y que incluso la propia Corte Interamericana ha dicho que este tipo de decisiones resulta en ocasiones "improcedente", haciendo referencia a los fallos "Aloebetoe Vs. Suriname" del año 1993 y "Blake vs. Guatemala" de 1999.

De lo expuesto por la CSJN surge una premisa y una posición política más que notoria: la Corte Interamericana no puede "revocar" sentencias de tribunales nacionales. A su vez, esta polémica posición, es justificada mediante la invocación de fallos de la Corte IDH en donde el tribunal interamericano afirmó que -en algunas oportunidades- sus propios pronunciamientos, cómo modo de reparación, no pudieron ser cumplidos.

Estas citas jurisprudenciales resultan totalmente alejadas de lo efectivamente resuelto en aquellos casos, dado que allí las sentencias de la Corte se referían a hechos claramente distintos al de estudio y no a la potestad de un Estado "de limitar o no" los efectos de un fallo.

d) Alcance del derecho público interno por sobre el derecho internacional. Interpretación del art. 27 de la CN.

Para la Corte, los instrumentos internacionales deben ajustarse a la "esfera de reserva soberana" indicada por el constituyente en el art. 27 de la Constitución, en la que se encuentran los principios de derecho público local, en base a ello no resulta posible que la Corte Interamericana modifique una decisión de la Corte Nacional pasada en autoridad de "cosa juzgada" (considerando $\mathrm{N}^{\circ} 16$ ). Con posterioridad, afirma que, entre dichos principios, se encuentra el carácter de la CSJN como órgano supremo local y cabeza del Poder Judicial, por lo que privarlo de esos caracteres y sustituirlo por un órgano internacional, atentaría contra lo dispuesto en los arts. 27 y 108 de la $\mathrm{CN}$ (considerando $\mathrm{N}^{\circ} 17$ ).

Finalmente, el voto culmina, luego de invocar citas de Joaquín V. González y Carlos Saavedra Lamas, con una interpretación 
del art. 27 de la CN, en la que se sostiene que el constituyente de 1994, al incorporar los tratados internacionales con jerarquía constitucional lo hizo reafirmando "la plena vigencia del derecho público como valladar infranqueable para los tratados internacionales" (considerando $\mathrm{N}^{\circ} 19$ ).

\section{Nueva integración de la CSJN: cambio de posición respecto al alcance del derecho internacional de los derechos humanos}

Lo resuelto por el máximo tribunal argentino marca sin lugar a dudas una tendencia que se perfila en la nueva composición de la Corte Nacional: (i) la imposición del derecho público nacional sobre el derecho interno y (ii) un claro freno a la tendencia "aperturista" del derecho internacional de los derechos humanos por el que venía transitando la vieja composición del tribunal.

Esto, tal vez, podía avizorarse de la lectura de algunas de las impugnaciones presentadas en el proceso de selección de los nuevos integrantes (Rosatti y Rosenkratz), quienes fueron criticados por poseer "posiciones restrictivas" respecto al alcance del derecho internacional de los derechos humanos y al uso del "control de convencionalidad", que aquí "ratifican".

El valor de las decisiones de organismos internacionales, no resulta materia novedosa en la jurisprudencia de la Corte Suprema de Justicia de la Nación, por el contrario, tal como se aprecia en el voto de Maqueda, en los últimos 15 años, existieron diferentes pronunciamientos que indicaron una progresiva apertura de nuestro ordenamiento nacional al derecho internacional de los derechos humanos, los cuales contaban en su mayoría con un factor común: la invocación como primer medida al principio de derecho internacional público denominado "Pacta sut servanda", que indica que si un Estado ha firmado y ratificado un instrumento internacional, debe ser

6 Ver http://cels.org.ar/documentos/Impugnaci\%C3\%B3n.pdf 
cumplido e interpretado de "buena fe" (artículos 26 y 31 de la Convención de Viene sobre Derecho de los Tratados).

Fallos trascendentes de la antigua composición de la Corte respecto al alcance del derecho internacional de los derechos bumanos

\begin{tabular}{|l|l|}
\hline 1. "Espósito" & $\begin{array}{l}\text { Este fallo marcó la primera oportunidad en que la antigua } \\
\text { composición de la Corte inició el camino de apertura del } \\
\text { derecho internacional de los derechos humanos, así, con un } \\
\text { alcance totalmente distinto al fallo de análisis, la CSJN sostu- } \\
\text { vo que en el caso la decisión de la Corte IDH resultaba "de } \\
\text { cumplimiento obligatorio para el Estado argentino (art. 68.I, } \\
\text { CADH), por lo cual también esta Corte, en principio, debe } \\
\text { subordinar el contenido de sus decisiones a las de dicho } \\
\text { tribunal internacional". (a) }\end{array}$ \\
\hline $\begin{array}{l}\text { 2. "Simón" } \\
\text { (2005) }\end{array}$ & $\begin{array}{l}\text { El criterio establecido en "Espósito" fue reafirmado con pos- } \\
\text { terioridad en el Caso "Simón"(2005) en el cual estableció } \\
\text { que tanto la jurisprudencia de la Corte IDH como las direc- } \\
\text { tivas de la CIDH constituyen una "imprescindible pauta de } \\
\text { interpretación de los deberes y obligaciones derivados de la } \\
\text { Convención Americana sobre Derechos Humanos". (b) Aquí, } \\
\text { fue notable el cambio de lenguaje utilizado por el supremo } \\
\text { tribunal nacional, que ya no aludía a una "guía" como la } \\
\text { había sostenido en la década de 1990. (c) }\end{array}$ \\
\hline 3. "Mazzeo" & $\begin{array}{l}\text { Aquí, la CSJN se refirió por primera vez en forma expresa } \\
\text { al "control de convencionalidad", una creación doctrinaria } \\
\text { de la Corte Interamericana que obliga a todos los jueces } \\
\text { nacionales firmantes del Pacto de San José a ejercer un } \\
\text { control de la Convención Americana. En sus decisiones. } \\
\text { Así, sostuvo lo siguiente: "El Poder Judicial debe ejercer una } \\
\text { especie de control de convencionalidad entre las normas } \\
\text { jurídicas internas que aplica en los casos concretos y la Con- } \\
\text { vención Americana sobre Derechos Humanos. En esta tarea, } \\
\text { el Poder Judicial debe tener en cuenta no sólo el tratado, } \\
\text { sino también la interpretación que del mismo ha hecho la } \\
\text { Corte Interamericana, intérprete último de la Convención } \\
\text { Americana".(d) }\end{array}$ \\
\hline
\end{tabular}




\begin{tabular}{|c|c|}
\hline $\begin{array}{l}\text { 4. "Videla" } \\
\text { (2010) }\end{array}$ & $\begin{array}{l}\text { En este pronunciamiento, la CSJN confirmó su tendencia de } \\
\text { apertura al Sistema Interamericano de Derechos Humanos, } \\
\text { afirmando lo siguiente: “...esta Corte ha precisado que a } \\
\text { los efectos de resguardar las obligaciones asumidas por el } \\
\text { Estado Argentino en el Sistema Interamericano de protec- } \\
\text { ción de los derechos humanos, la jurisprudencia de la Corte } \\
\text { Interamericana es una insoslayable pauta de interpreta- } \\
\text { ción para los poderes constituidos argentinos en el ámbito } \\
\text { de su competencia y que dicho tribunal internacional ha } \\
\text { considerado que el Poder Judicial debe ejercer una especie } \\
\text { de control de convencionalidad entre las normas jurídicas } \\
\text { internas que aplican en los casos concretos y la Convención } \\
\text { Americana sobre Derechos Humanos, tarea en la que deben } \\
\text { tener en cuenta no solamente el tratado sino también la } \\
\text { interpretación que del mismo ha hecho la Corte Interame- } \\
\text { ricana, intérprete última de la Convención Americana” (el } \\
\text { subrayado me pertenece). (e) }\end{array}$ \\
\hline $\begin{array}{l}\text { 5. "Rodríguez } \\
\text { Pereyra } \\
\text { c/Ejército } \\
\text { Nacional" } \\
\text { (2012) }\end{array}$ & 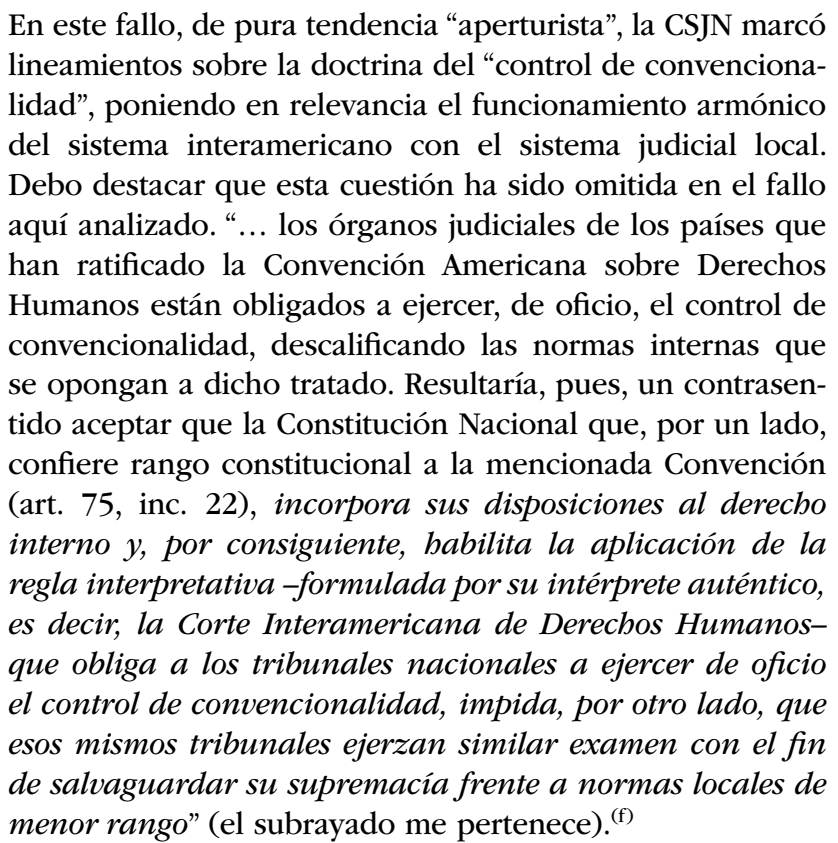 \\
\hline
\end{tabular}




\begin{tabular}{|c|c|}
\hline $\begin{array}{l}\text { 6. Carranza } \\
\text { Latrubesse } \\
\text { (2013) }\end{array}$ & $\begin{array}{l}\text { El más alto tribunal nacional -en su voto mayoritario- postu- } \\
\text { ló la obligatoriedad de cumplir en toda circunstancia con los } \\
\text { informes "del artículo } 51 \text { " de la Comisión Interamericana }{ }^{(\mathrm{g})} \\
\text { y, en el caso, con las recomendaciones formuladas en el } \\
\text { informe } \mathrm{N}^{\circ} 30 / 97 \text {, }{ }^{\text {(h) }} \text { por lo que el Estado debió indemnizar } \\
\text { al actor ante el incumplimiento de dicho informe. En su re- } \\
\text { solución sostuvo lo siguiente: "si un Estado suscribe y ratifica } \\
\text { un tratado internacional, especialmente si trata de Derechos } \\
\text { Humanos, como es el caso de la Convención Americana, tiene } \\
\text { la obligación de realizar sus mejores esfuerzos para aplicar } \\
\text { las recomendaciones de un órgano de protección como la } \\
\text { Comisión que es, además, uno de los órganos principales de } \\
\text { la Organización de los Estados Americanos (OEA)". }{ }^{(i)}\end{array}$ \\
\hline $\begin{array}{l}\text { 7. Mohamed } \\
\text { (2015) }\end{array}$ & $\begin{array}{l}\text { En este última decisión, la CSJN sostuvo -en una posición } \\
\text { totalmente contraria a la afirmada en "Fontevecchia"- que: } \\
\text { “... a partir de la reforma constitucional de } 1994 \text {, de acuerdo } \\
\text { con lo dispuesto en el art.75, inc. } 22^{\circ} \text {, de la norma fun- } \\
\text { damental, las sentencias de la Corte Interamericana de } \\
\text { Derechos Humanos pronunciadas en causas en las que el } \\
\text { Estado argentina sea parte deben ser cumplidas por los } \\
\text { poderes constituidos en el ámbito de su competencia y, en } \\
\text { consecuencia, son obligatorias para la Corte Suprema de } \\
\text { Justicia de la Naci6n. Por ella, esta Corte, como uno de los } \\
\text { poderes del Estado argentino conforme lo previsto en el } \\
\text { art. } 68.1 \text { de la misma Convenci6n, debe cumplir la sentencia } \\
\text { del tribunal internacional”. }{ }^{(j)}\end{array}$ \\
\hline \multicolumn{2}{|c|}{ 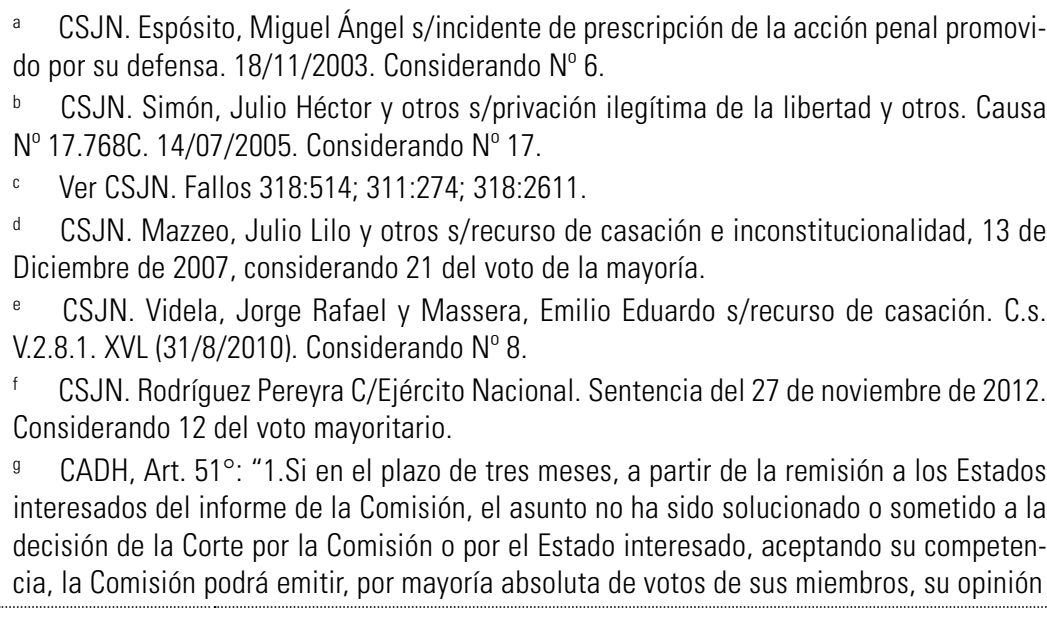 } \\
\hline
\end{tabular}


y conclusiones sobre la cuestión sometida a su consideración. 2. La Comisión hará las recomendaciones pertinentes y fijará un plazo dentro del cual el Estado debe tomar las medidas que le competan para remediar la situación examinada. 3. Transcurrido el período fijado, la Comisión decidirá, por la mayoría absoluta de votos de sus miembros, si el Estado ha tomado o no medidas adecuadas y si publica o no su informe".

h CIDH. Informe N $\mathrm{N}^{0}$ 30/97. Disponible en https://www.cidh.oas.org/annualrep/97span/ Argentina10.087.htm, acceso 8 de junio de 2015.

CSJN. Carranza Latrubesse c/Estado Nacional. 6/8/2013. Considerando № 3.

j CSJN. Resolución 477/15. Considerando VI.

Para finalizar este punto, la postura que adoptaba la antigua composición de la CSJN fue también compartida por varios tribunales de la más alta jerarquía en la región, tales como la Sala Constitucional de la Corte Suprema de Justicia de Costa Rica, ${ }^{7}$ el Tribunal Constitucional de Bolivia, ${ }^{8}$ el Tribunal Constitucional del Perú, ${ }^{9}$ la Corte Constitucional de Colombia, ${ }^{10}$ la Suprema Corte de la Nación de México $^{11}$ y la Corte Suprema de Panamá, ${ }^{12}$ los cuales otorgan un criterio de apertura y obligatoriedad respecto a las interpretaciones efectuadas por la Corte Interamericana en relación a las decisiones en la justicia doméstica.

7 Sala Constitucional de la Corte Suprema de Justicia de Costa Rica. Acción Inconstitucional. Voto 2313-95 (Expediente 0421-S-90), Sentencia de 9 de mayo de 1995, considerando VII.

8 Tribunal Constitucional de Bolivia (Expediente No. 2006-13381-27-RAC). Sentencia emitida el 10 de mayo de 2010, apartado III.3. sobre "El Sistema Interamericano de Derechos Humanos. Fundamentos y efectos de las Sentencias emanadas de la Corte Interamericana de Derechos Humanos".

9 Tribunal Constitucional del Perú .Sentencia emitida el 21 de julio de 2006 (Expediente No. 2730-2006-PA/TC), fundamento 12 y sentencia 00007-2007-PI/TC emitida el 19 de junio de 2007 por el Pleno del Tribunal Constitucional del Perú (Colegio de Abogados del Callao c. Congreso de la República), fundamento 26.

10 Corte Constitucional de Colombia. Sentencia C-010/00 emitida el 19 de enero de 2000, párr. 6.

11 Pleno de la Suprema Corte de Justicia de la Nación de México, Expediente Varios 912/2010, decisión de 14 de julio de 2011.

12 Corte Suprema de Justicia de Panamá, Acuerdo No. 240 de 12 de mayo de 2010, mediante el cual se da cumplimiento a la sentencia de 27 de enero de 2009, de la Corte Interamericana de Derechos Humanos en el caso Santander Tristán Donoso contra Panamá. 
Postura contraria ha adoptado, por ejemplo, la Corte de Venezuela $^{13}$, la cual posee un criterio similar al que pareciera brindar ahora la corte argentina, restringiendo el alcance de las sentencias emanadas del más alto tribunal interamericano. Al respecto, cabe agregar que esta es una de las razones por las que el país "bolivariano" se retiró del Sistema Interamericano de derechos humanos en el año 2013.

\section{El procedimiento de supervisión de la Corte Interamericana: la audiencia pública}

Retornado a los vaivenes del caso en estudio, vale decir que luego del pronunciamiento de la Corte Nacional, la cuestión continuó en el plano interamericano. Es que con posterioridad a cada sentencia de fondo que dicte la Corte IDH, el mismo tribunal realiza un mecanismo de seguimiento a los fines de verificar el cumplimiento de lo oportunamente dispuesto. Dicho procedimiento se encuentra regulado en el art. 63 del Reglamento de la Corte $\mathrm{IDH}^{14}$ y, como modo de seguimiento, prevé la realización de audiencias (si es que el tribunal lo considera pertinente).

En este marco, luego de que los representante de la víctima denunciaran el incumplimiento del Estado argentino a raíz de la sentencia de la CSJN, la Corte IDH resolvió convocar a una

\footnotetext{
13 Ver por ejemplo caso Corte IDH, Caso Apitz Barbera y otros ("Corte Primera de lo Contencioso Administrativo") Vs. Venezuela.

14 Reglamento Corte IDH. Artículo 63. Supervisión de cumplimiento de sentencias y otras decisiones del Tribunal 1. La supervisión de las sentencias y demás decisiones de la Corte se realizará mediante la presentación de informes estatales y de las correspondientes observaciones a dichos informes por parte de las víctimas o sus representantes legales. La Comisión deberá presentar observaciones al informe del Estado y a las observaciones de las víctimas o sus representantes. 2. La Corte podrá requerir a otras fuentes de información datos relevantes sobre el caso, que permitan apreciar el cumplimiento. Para los mismos efectos podrá también requerir las pericias e informes que considere oportunas. 3. Cuando lo considere pertinente, el Tribunal podrá convocar a las partes a una audiencia para supervisar el cumplimiento de sus decisiones. 4. Una vez que el Tribunal cuente con la información pertinente, determinará el estado del cumplimiento de lo resuelto y emitirá las resoluciones que estime pertinentes.
} 
audiencia con las autoridades del Estado, la Comisión Interamericana y los representantes de las víctimas, la cual se llevó a cabo el día el 21 de agosto de 2017 en la sede del Tribunal costarricense $\mathrm{e}^{15}$.

En la audiencia pública, el Estado - a través de sus representantes- "ratificó" "la obligatoriedad de las decisiones adoptadas por la Corte Interamericana [...] en todos sus términos". Respecto a dejar sin efecto la condena civil, el Estado afirmó que, en virtud del principio de la separación de poderes, en la República Argentina "la Corte Suprema argentina [...] es quien tiene que resolver este tema porque implicaba la intervención de un expediente judicial", por lo que "la Corte Suprema es el Estado argentino". Afirmó que "el Poder Ejecutivo no puede [...] arrogarse funciones judiciales"; que no es un tema de "falta de voluntad", sino que "no tiene posibilidad de bacer nada más", ya que "no tiene herramientas de derecho interno que le permitan hacer algo diferente a lo ya hecho". Afirmó que, "por tal razón, nada tenía ni podía agregar el Estado argentino en esta instancia a través de su órgano ejecutivo a lo expuesto por su órgano judicial máximo actuando dentro del ámbito de sus potestades y atribuciones constitucionales, en aquella sentencia que fuera remitida oportunamente".

Por su parte, los representantes de las víctimas informaron "amplios" argumentos respecto a las razones por las cuales consideran que la decisión de la Corte Suprema de 14 de febrero de 2017 implica un "manifiesto incumplimiento" de la Sentencia

15 En esta audiencia comparecieron: a) por el Estado: Javier Salgado, Agente, Director de la Dirección Contencioso Internacional en Materia de Derechos Humanos del Ministerio de Relaciones Exteriores, Siro de Martini, Asesor de Asuntos Internacionales de Derechos Humanos del Ministro de Justicia y Derechos Humanos, y Ramiro Badía, Coordinador de la Dirección Nacional de Asuntos Jurídicos en Materia de Derechos Humanos del Ministerio de Justicia y Derechos Humanos; b) por los representantes de las víctimas: Diego Morales, Director del Área de Litigio y Defensa Legal del CELS y Damián Loreti, Secretario de la Comisión Directiva de dicha organización, y c) por la Comisión Interamericana: Francisco José Eguiguren Praeli, Presidente, Edison Lanza, Relator Especial para la Libertad de Expresión, y Selene Soto Rodríguez, abogada de la Secretaría Ejecutiva. La grabación de la audiencia pública se encuentra disponible en el siguiente enlace: https://vimeo.com/230510053. 
de la Corte Interamericana respecto a la reparación relativa a dejar sin efecto la atribución de responsabilidad civil a las víctimas, así como que también implica un "grave retroceso en la jurisprudencia de la Corte Suprema de Justicia que pone a Argentina al margen de sus compromisos internacionales", $\mathrm{y}$ que tiene efectos que "exceden por mucho el caso de referencia y plantean un cuadro de debilitamiento general de la protección de derechos humanos en la Argentina".

Finalmente, los representantes de la $\mathrm{CIDH}$ expresaron que "la decisión de la Suprema Corte Argentina es un grave obstáculo para el cumplimiento de la Sentencia de la Corte Interamericana, cuyas implicancias trascienden al caso". Al respecto sostuvo, entre otros argumentos, que "el desconocimiento por parte del máximo tribunal argentino de la competencia de la Corte Interamericana en este caso, vulnera el derecho de las víctimas [...], dado que no ha cesado la violación en su perjuicio, [y ...] también genera un efecto sistémico regresivo más general para Argentina, en tanto desconoce la exhaustiva ponderación realizada por la Corte Interamericana".

\section{La sentencia de supervisión de (in)cumplimiento de la Corte IDH}

Luego de oídas las distintas posiciones y analizadas las constancias del caso, la Corte IDH emitió su sentencia de supervisión de cumplimiento el día 18 de octubre de 2017. Allí, consideró que el Estado no había cumplido con las medidas de reparación dispuestas en su sentencia sobre el fondo, y ordenó cumplirlas.

El fallo, además, deja algunos puntos interesantes de análisis que a continuación pasaré a sintetizar:

a) Obligatoriedad de las decisiones de la Corte

Interamericana. La "cosa juzgada internacional"

En el párrafo $13^{\circ}$ del pronunciamiento, la Corte IDH reafirmó que, de conformidad con lo establecido en el artículo 67 de la CADH "el fallo de la Corte será definitivo e inapelable" y 
produce los efectos de "autoridad de cosa juzgada internacional". Además estableció que el cumplimiento de lo dispuesto en la sentencia es una obligación que no está sujeta a condiciones, ya que de conformidad con lo establecido en el artículo 68.1 de la Convención Americana, "[l]os Estados Partes en la Convención se comprometen a cumplir la decisión de la Corte en todo caso en que sean partes". Y agregó "Dichos Estados tienen la obligación convencional de implementar tanto en el ámbito internacional como interno y de forma pronta e integra, lo dispuesto por el Tribunal en las Sentencias, y de no cumplirse se incurre en un ilícito internacional. Las obligaciones convencionales de los Estados Parte vinculan a todos los poderes y órganos del Estado, es decir, que todos los poderes del Estado (Ejecutivo, Legislativo, Judicial, $u$ otras ramas del poder público) y otras autoridades públicas o estatales, de cualquier nivel, incluyendo a los más altos tribunales de justicia de los mismos, tienen el deber de cumplir de buena fe con el derecho internacional" ${ }^{16}$.

Por otra parte, en el párrafo $14^{\circ}$ el tribunal estableció que "Los Estados Parte en la Convención no pueden invocar disposiciones del derecho constitucional $u$ otros aspectos del derecho interno para justificar una falta de cumplimiento de las obligaciones contenidas en dicho tratado"; y frente a la postura soberanista de la CSJN dijo que "...en lo concerniente al cumplimiento de las sentencias de la Corte, no se trata de resolver el problema de la supremacía del derecho internacional sobre el nacional en el orden interno, sino únicamente de hacer cumplir aquello a lo que los Estados soberanamente se comprometieron"17.

b) "Dejar sin efecto" no es sinónimo de "revocar"

Por otro lado, la Corte IDH sostiene que "dejar sin efecto" la sentencia, como medida reparatoria, no implicaba necesariamente

16 Corte IDH. Caso Fontevecchia y D'amico vs. Argentina. Sentencia de supervisión de cumplimiento. Párr. 13

17 Corte IDH. Ídem. Párr. 14. 
"revocar" el fallo. Así, sostuvo que "la Corte Suprema interpretó que lo solicitado era sinónimo de revocar la sentencia emitida por dicho tribunal interno en el 2001" y recordó que esa misma reparación de "dejar sin efectos" sentencias internas "ba sido cumplida por otros Estados y por Argentina en casos similares a éste, en los que se constató una violación a la Convención Americana por la imposición judicial de responsabilidades penales o civiles ulteriores contrarias al derecho a la libertad de pensamiento y de expresión ${ }^{18} " 19$.

Lo novedoso del fallo, es que la Corte IDH seguidamente le demostró al Estado las posibles soluciones que podría haber adoptado para "dejar sin efecto" la sentencia. Así expresó que: "El estado podría adoptar algún otro tipo de acto jurídico, diferente a la revisión de la sentencia, para dar cumplimiento a la medida de reparación ordenada, como por ejemplo la eliminación de su publicación de la páginas web de la Corte

18 En el caso Herrera Ulloa se ordenó a Costa Rica "dejar sin efecto, en todos sus extremos, la sentencia [penal condenatoria] emitida el 12 de noviembre de 1999 por el Tribunal Penal del Primer Circuito Judicial de San José" en perjuicio del señor Mauricio Herrera Ulloa. En el caso Palamara Iribarne se ordenó a Chile "dejar sin efecto [... . en todos sus extremos, las sentencias condenatorias emitidas en contra del señor Humberto Antonio Palamara Iribarne: la sentencia de 3 de enero de 1995 de la Corte Marcial de la Armada en la Causa Rol No. 471 por el delito de desacato y las sentencias emitidas por dicha Corte Marcial [...] el 3 de enero de 1997 y por el Juzgado Naval de Magallanes el 10 de junio de 1996 por los delitos de desobediencia e incumplimiento de deberes militares". En el caso Kimel se ordenó a Argentina "dejar sin efecto la condena penal impuesta al señor Kimel y todas las consecuencias que de ella se deriv[aran]". Para ello el Estado debía dejar sin efecto "la sentencia condenatoria emitida en contra del señor Kimel[, que] implicó la violación de su derecho a la libertad de expresión en todos sus extremos]". En el caso Tristán Donoso se ordenó a Panamá "dejar sin efecto la condena penal impuesta al señor Santander Tristán Donoso y todas las consecuencias que de ella se deriv[aro]n". Cfr. Caso Herrera Ulloa Vs. Costa Rica. Excepciones Preliminares, Fondo, Reparaciones y Costas. Sentencia de 2 de julio de 2004. Serie C No. 107, punto resolutivo cuarto; Caso Palamara Iribarne Vs. Chile. Fondo, Reparaciones y Costas. Sentencia de 22 de noviembre de 2005. Serie C No. 135, punto resolutivo décimo segundo; Caso Kimel Vs. Argentina. Fondo, Reparaciones y Costas. Sentencia de 2 de mayo de 2008. Serie C No. 177, punto resolutivo séptimo, y Caso Tristán Donoso Vs. Panamá. Excepción Preliminar, Fondo, Reparaciones y Costas. Sentencia de 27 de enero de 2009. Serie C No. 193, punto resolutivo décimo cuarto.

19 Corte IDH. Caso Fontevecchia y D'amico vs. Argentina. Sentencia de supervisión de cumplimiento. Párr. 20 
Suprema de Justicia y del Centro de Información Judicial, o que se mantenga su publicación pero se le realice algún tipo de anotación indicando que esa sentencia fue declarada violatoria de la Convención Americana por la Corte Interamericana"20.

c) Consideraciones de la Corte IDH frente a las afirmaciones de la CSJN

Seguidamente, la Corte IDH se detiene a analizar los considerandos del fallo de la CSJN y afirma ${ }^{21}$ :

- Que la CSJN se atribuyó competencias que no le corresponden, pues la obligatoriedad surge del derecho internacional, de la Convención Americana y del reconocimiento de la competencia de la Corte IDH (párrafo 23).

- Que la Corte IDH ya ha determinado que la obligatoriedad de sus fallos no puede quedar al arbitrio de un órgano del Estado -especialmente de aquél que generó la violación-, pues se generarían restricciones que harían inoperante la función del tribunal internacional (párrafo 24).

- Que la posición de la CSJN "contrasta ampliamente con su linea jurisprudencial anterior, la cual había sido destacada por este Tribunal como un ejemplo positivo en cuanto al reconocimiento que ban becho tribunales de la más alta jerarquía de la región sobre el carácter vinculante de las Sentencias de la Corte Interamericana y a la aplicación del control de convencionalidad teniendo en cuenta interpretaciones efectuadas por ésta” Así, destacó que las decisiones adoptadas por la CSJN en los años 2004 y 2011 en los casos "Bulacio" y "Bueno Alves", permitieron avanzar con la obligación de investigar ordenada en esos casos, al "dejar sin efecto" o "revocar", respectivamente, decisiones de tribunales inferiores (párrafo 25).

\footnotetext{
20 Corte IDH. Ídem. Párr. 21

21 Recomiendo la lectura del blog de Alberto Bovino "No Hubo Derecho" sobre el tema. Disponible en: http://nohuboderecho.blogspot.com.ar/search?updated-max=2017-1106T15:48:00-03:00\&max-results=13
} 
- Que cuando la CSJN afirmó que la obligatoriedad de las sentencias de la Corte IDH está condicionada a aquellas que hayan sido dictadas "dentro del marco de sus potestades remediales", se arrogó una función que no le corresponde, la de determinar cuándo ese Tribunal actúa en el marco de sus competencias (párrafo 26).

- Que frente a lo dicho por la CSJN en cuanto afirma que la medida dispuesta por la Corte IDH constituye "un mecanismo restitutivo que no se encuentra previsto por el texto convencional", la Corte interamericana reafirmó su competencia para ordenar las medidas reparatorias en base a lo dispuesto en los arts. 63.1 de la CADH y a los principios de derecho internacional de los derechos humanos (párrafos 27 a 29).

- Que en el caso era posible la restitución de la situación anterior a la violación denunciada dado que se trataba dejar sin efecto una sentencia de índole civil (párrafo 30).

- Que la CSJN, al rechazar la facultad de la Corte IDH prefiere dejar subsistente un acto jurisdiccional violatorio de la $\mathrm{CADH}$ porque fue un acto emitido por el más alto tribunal de Argentina. Con ello, sugeriría que es el único tribunal del Estado cuyas decisiones no pueden ser dejadas sin efecto a pesar de ser violatorias de derechos humanos. Para el derecho internacional es absolutamente irrelevante el órgano del Estado cuya acción u omisión causó el hecho internacionalmente ilícito, de manera tal que cualquier órgano del Estado, independientemente de sus funciones o jerarquía, puede generar la responsabilidad internacional del Estado (párrafo 31).

- Que al pronunciarse sobre decisiones judiciales internas, la Corte Interamericana no actúa como una cuarta instancia revisora de las sentencias dictadas por los tribunales internos, sino que determina si éstos han incurrido en sus decisiones en alguna violación de los derechos humanos $\mathrm{u}$ obligaciones internacionales reconocidos en los 
tratados sobre los cuales este Tribunal tiene competencia (párrafo 31).

- Que con respecto al alcance del principio "subsidiariedad" del sistema interamericano de derechos humanos que brindó la CSJN, la Corte IDH reafirma que ésta sólo puede ser exigida en el ámbito internacional después de que el Estado haya tenido la oportunidad de declarar la violación y reparar el daño ocasionado por sus propios medios en el ámbito nacional y aclara que, en el presente caso, precisamente porque la violación no se resolvió ni se reparó en el ámbito interno, las víctimas activaron los mecanismos de protección internacional, los cuales no pretendían sustituir a las jurisdicciones nacionales, sino complementarlas en la protección de derechos humanos (párrafo 32).

- Finalmente, la Corte IDH recordó que corresponde al Estado asegurar que no se torne ilusoria la efectividad del Sistema Interamericano al someter a las víctimas a un complejo proceso a nivel internacional, para que después del mismo, quede al arbitrio de órganos del Estado cuándo deben ser cumplidas las reparaciones ordenadas para subsanar la violación en su perjuicio. La ejecución de las Sentencias de la Corte Interamericana es parte fundamental del derecho de acceso a la justicia internacional. Lo contrario supone la negación misma de este derecho para víctimas de violaciones de derechos humanos que se encuentran amparadas por una sentencia de la Corte Interamericana (Párrafo 35).

Con estas consideraciones, la Corte IDH resolvió mantener abierto el procedimiento de supervisión de cumplimiento respecto de las medidas de reparación ordenadas y dispuso que el Estado presente, a más tardar el 28 de febrero de 2018, un informe en el cual indique todas las medidas adoptadas para cumplir con las reparaciones ordenadas que se encuentran pendientes de cumplimiento. 


\section{Conclusiones}

Sin lugar a dudas, los operadores jurídicos argentinos nos encontramos actualmente frente a complejo entramado respecto al alcance que poseen los pronunciamientos de los organismos del Sistema Interamericano, en especial, las sentencias de la Corte IDH, dado que nos situamos ante dos pronunciamientos contundentes, rígidos y, por sobre todo, contradictorios. El margen de apreciación de los fallos del organismo interamericano claramente se ha debilitado en el derecho interno con la nueva postura de la CSJN.

Por otro lado, esta incertidumbre también es producto de la propia contradicción de la Corte nacional dado que, por un lado afirmó que las sentencias de la Corte IDH son "vinculantes" y "obligatorias", pero de seguido estableció que es facultad suya establecer si las mismas son dictadas en "el marco" de la competencia convencional. En otros términos, pareciera ser que es la propia Corte quien por imperio propio tiene la potestad actual de decidir "si cumple o no cumple" con lo dictado en dichas sentencias, aunque vimos que la Corte IDH deslegitimó dicho criterio. Como afirma el constitucionalista Gustavo Arballo "esto es muy peligroso, porque si vamos a interpretar las sentencias de la Corte Interamericana con esta lógica mezquina todo el sistema sería inoficioso -y el mismo Ejecutivo, este u otro cualquiera, podría invocar esta idea para decir, cada vez que no le simpatice, que el Tribunal obró fuera de sus potestades remediales"22.

En peor posición, por su propia naturaleza, se encuentra las decisiones que emanan de la Comisión Interamericana de Derechos Humanos (CIDH), dado que si la internalización de las decisiones de un tribunal con competencia contenciosa, como lo es Corte IDH, es interpretada de manera restrictiva, más aún lo serán las decisiones del organismo con sede en Washington que no sólo emite informes sino también adopta medidas cautelares.

22 http://www.saberderecho.com/ 
Sin pretender un análisis de otra índole, el incumplimiento de la medida cautelar otorgada a favor de Milagros Sala es un claro espejo de tal situación ${ }^{23}$.

En efecto, ante este nuevo escenario jurisprudencial, con total seguridad, si el Estado mantiene su postura, surgirán un sin números de inconvenientes en la ejecución de sentencias contra el Estado argentino cada vez que un organismo del sistema de protección internacional de derechos humanos ordené "dejar sin efecto" una pronunciamiento judicial doméstico pasado en autoridad de "cosa juzgada". Recordemos aquí, que la mayor cantidad de casos en el Sistema Interamericano que posee el Estado argentino giran en torno a denuncias de violaciones a las garantías judiciales (art. 8 de la $\mathrm{CADH}$ ) y a la protección judicial (art. 25.de la CADH), por lo que es altamente probable que la discusión se repita de seguirse la misma receta.

Por otro lado, como afirma la Corte IDH, el fallo de la corte local viene a colocar una enorme barrera al uso del "control de convencionalidad" por parte de los jueces inferiores, doctrina que se viene propagando desde hace más de 10 años en diferentes sectores académicos en todo el continente y que como vimos en los puntos anteriores fue receptada por la CSJN ¿Habrá algún juez valiente que se anime a aplicar la doctrina de la Corte IDH cuando haya colisión entre una norma local

\footnotetext{
23 El 27 de julio de 2017, tras haber recibido información de ambas partes y haber efectuado una visita al centro de detención, la Comisión Interamericana otorgó medidas cautelares a favor de Milagro Sala a través de la Resolución 23/17. A juicio de la Comisión, existían suficientes elementos para considerar que, entre otros aspectos, las condiciones de detención de Milagro Sala constituían una situación de hostigamiento y estigmatización que ponía en riesgo su vida e integridad, situación agravada por el estado de la salud mental de la beneficiaria. Por lo anterior, la CIDH dispuso que el Estado argentino debía adoptar medidas para garantizar los derechos a la vida e integridad personal de la beneficiaria; concertar con ella las medidas a tomar; y teniendo en cuenta la excepcionalidad de la detención preventiva, adoptar medidas alternativas, tales como el arresto domiciliario o que la beneficiaria Sala enfrentara el proceso en libertad. Luego de otorgamiento, el 3 de noviembre de 2017, la Comisión Interamericana de Derechos Humanos (CIDH) solicitó a la Corte Interamericana de Derechos Humanos (CortelDH) que adopte medidas provisionales a favor de Milagro Sala con respecto al Estado de Argentina, porque considera que el Estado ha incumplido las medidas cautelares dictadas en su favor.
} 
y la CADH? Pese a ello la sentencia de supervisión alienta a continuar su uso.

Lo cierto es que esta disputa entre cortes recién tuvo su segundo capítulo de la saga (o cuarto, desde donde se mire) y continuará el 18 de febrero de 2018 cuando venza el plazo para que el Estado presente sus informes. Todo pareciera indicar que de continuarse en esa rígida posición (incumplimiento de las medidas reparatorias), el caso termine resolviéndose en el ámbito de la asamblea de la Organización de Estados America$\operatorname{nos}^{24}$, o en un catastrófico escenario, con un Estado retirándose del Sistema Interamericano de Derechos Humanos, tal como lo hizo en su momento Perú y, como enuncié previamente, Venezuela.

Sin embargo, en este caso en particular, la Corte IDH (pese a no estar de acuerdo con la postura de la CSJN) le abrió las puertas al Estado argentino mostrándole amablemente las "cartas" con las que podría cumplir las medidas y así continuar la relación armónica entre los dos ordenamientos. Como afirma Andrés Gil Dominguez “...la Corte Interamericana de Derechos Humanos le ofrece a la Corte Suprema de Justicia una salida razonada y lógica -dentro del diálogo interjurisdiccional que planteó oportunamente Rosatti- para que esta retome el sendero de la tutela útil y progresiva de los derechos bumanos, el acatamiento de las sentencias condenatorias del Estado argentino y la expansión del control de convencionalidad interno"25.

En definitiva, ante esta nueva oportunidad que brinda la Corte IDH, lo más deseable es que el Estado argentino cumplimente lo ordenado y sugerido en la sentencia de supervisión. Desperdiciar esa oportunidad sería realmente incomprensible y agregaría una nueva injustificada regresión en la materia ${ }^{26}$.

\footnotetext{
24 Conforme lo dispone el artículo 65 de la CADH.

25 Gil Domínguez, Andrés. "La Corte Interamericana de Derechos Humanos reafirma su competencia y el alcance del control de convencionalidad externo en el caso "Fontevecchia". Disponible en http://underconstitucional.blogspot.com.ar/
}

26 Gil Domínguez, Andrés. Idem. 
En rigor, ante este panorama que pareciera significar una etapa de retroceso en materia de protección de derechos humanos producto de los flamantes cambios jurisprudenciales de la nueva integración de la CSJN - que pareciera evidenciar también en el fallo "Muiña" ${ }^{27}$-, sumada a la incertidumbre actual que reina respecto al valor interpretativo de las decisiones de los organismos mencionados, entiendo que es el Congreso de la Nación quien debe adecuar las normas procesales y sustanciales a los derechos establecidos en los instrumentos internacionales de derechos humanos. El ejercicio efectivo de estos roles por parte del Poder Legislativo permite una mejor y mayor protección de los derechos de la ciudadanía a nivel nacional y su acción posibilitaría que exista una mejor articulación entre la protección regional y nacional de derechos humanos, de modo de contar con un sistema integrado de protección efectivo $^{28}$.

La cuestión central no sólo se reduce al valor restringido que ahora el máximo tribunal nacional le otorgó a estos instrumentos como elementos interpretativos "en abstracto", sino que también el problema se torna más complejo cuando hablamos de ejecución de sentencias en los casos "en concreto". Frente a este vacío interpretativo, la Corte Interamericana ha sostenido que: "Corresponde a los Estados expedir las normas $y$ ajustar las prácticas para cumplir lo ordenado en las decisiones de la Corte Interamericana, si no cuentan con dichas disposiciones" 29 .

El establecimiento de órganos y el desarrollo de políticas y procedimientos que aseguren el cumplimiento cabal de las decisiones del Sistema Interamericano es un requerimiento de

27 CSJN 1574/2014/RHI. Autos "Bignone, Reynaldo Benito Antonio y otro s/recurso extraodinario". En este pronunciamiento la CSJN aplicó el beneficio de la ley conocida como " $2 \times 1$ " (ley 24.390-derogada-) para los delitos de lesa humanidad.

28 CEJIL. Implementación de las decisiones del Sistema Interamericano de Derechos Humanos: Aportes para los procesos legislativos. P. 11

29 Corte IDH. Caso García Prieto y otros v. El Salvador. Sentencia de 20 de noviembre de 2007. Serie C N 168, Voto razonado del Juez García Ramírez, párr. 4. 
la propia Convención Americana sobre Derechos Humanos ${ }^{30}$. Por ello, ante la nueva agenda de la Corte Nacional y lo expresado por la Corte IDH en la sentencia de supervisión, pese a no ser suficiente, es necesario que el Congreso argentino, en la misma senda que ha reaccionado frente al fallo "Muiña", lo haga ante la oscura situación que se plantea en "Fontevecchia" con las decisiones de los organismos del Sistema Interamericano, reinterpretando así el alcance del art. 75 inc. 22 de la CN y la fuerza de las decisiones de los organismos de protección del sistema, tanto en su valor interpretativo como en su faz de ejecución.

En suma, este "duelo de cortes" que se vislumbra en Fontevecchia resulta un enorme disparador de diversos temas que abarcan cuestiones de índole constitucional, convencional, derecho internacional y exige un profundo debate y análisis sobre la naturaleza propia del sistema interamericano de derechos humanos. Aunque parecía una verdad de perogrullo, todo indica que los operadores jurídicos debemos volver a recoger la lectura de los viejos debates de los constituyentes del 94' que decidieron jerarquizar la Convención Americana sobre Derechos Humanos incorporándola a nuestra Constitución Nacional.

\section{Síntesis final}

- Nos encontramos ante un diálogo entre Corte IDH y CSJN que aún no ha finalizado.

- La corte IDH advierte un retroceso en la nueva postura de la CSJN que puso freno a la tendencia "aperturista" del "derecho internacional de los derechos humanos";

- El resolutorio de la CSJN (i) debilita la protección a los derechos humanos en el orden interno, (ii) desalienta -de manera indirecta- el uso de la doctrina del "control de convencionalidad" y (iii) profundiza la crisis de "legitimidad" del Sistema Interamericano de Derechos Humanos, vapuleado y debilitado también por su grave situación financiera;

30 CEJIL. Ob. Cit. P. 16 
- La Corte Suprema se "auto-colocó" cómo el único poder soberano del Estado al cual no se le pueden "revisar" sus decisiones. La Corte IDH deslegitimó tal postura y le brindó una nueva posibilidad al Estado para que cumpla con las medidas reparatorias en el caso.

- El estado argentino se encuentra frente a una nueva posibilidad remediar su diálogo con el sistema interamericano de derechos humanos.

- Se continúa evidenciando un marco de incertidumbre sobre el valor interpretativo de las decisiones de los organismos del sistema interamericano y su modo de ejecución, por lo que para reforzar su acatamiento, resulta necesario que el Poder Legislativo adopte nuevos mecanismos que aseguren el cumplimiento efectivo de las obligaciones convencionales que Argentina ha asumido.

\section{Bibliografía utilizada}

CEJIL. Implementación de las decisiones del Sistema Interamericano de Derechos Humanos: Aportes para los procesos legislativos. Buenos Aires: Center for Justice and International Law - CEJIL, 2009;

Comas, Rocío; De Antoni, Román y otros [et al.]. Maestría en derechos humanos y democratización en América Latina y el Caribe: tesis destacadas del año académico 2014-2015 1a edición - San Martín : UNSAM EDITA, 2016. 